\title{
The differential effect of maternal dietary patterns on quantiles of Birthweight
}

\author{
Aweke A. Mitku ${ }^{1,4^{*}} \mathbb{D}$, Temesgen Zewotir ${ }^{1}$, Delia North ${ }^{1}$, Prakash Jeena ${ }^{2}$ and Rajen N. Naidoo ${ }^{3}$
}

\begin{abstract}
Background: Maternal dietary habits during pregnancy are considered essential for development and growth of the fetus as well as maternal health. It has an effect on the birthweight of infants. However, little is known about the effect of dietary patterns on birthweight in urban South Africa. This study aimed to investigate differential effect of dietary patterns of pregnant women on quantiles of birthweight.

Methods: Data for the study were obtained from a Mother and Child in the Environment birth cohort study in Durban South Africa. Quantile regression was used to investigate the effect of maternal dietary patterns on quantiles of birthweight. Data collection was conducted during the period of 2013 to 2017 in Durban South Africa. Using factor analysis, eight dietary groups were identified from 687 pregnant women in the cohort. Quantile regression analysis was employed to identify the differential effects of the seven dietary groups and demographic factors on the birthweight.
\end{abstract}

Results: The quantile regression estimates at the $50^{\text {th }}$ quantile and the ordinary regression estimates painted the same picture about the conditional mean effect of covariates on the birthweight. But unlike the quantile regression the ordinary regression fails to give insights about the covariates effect disparities at the low and/or upper birthweight quantiles. All the dietary groups show a significant differential effect at different birthweight quantiles. For instance, increased frequency of protein rich foods intake was associated with reduction in birthweight at lower and upper quantiles; increased frequency of junk foods intake has a slight increase in birthweight at the lower quantiles but significantly higher increase at the $95^{\text {th }}$ quantile $(p<0.001)$; increase in consuming vegetable rich foods, reduced birthweight at $95^{\text {th }}$ quantile $(p<0.001)$. The results further showed that employment $(p=0.006)$ and family size $(p=0.002)$ had differential effects across different birthweight quantiles.

Conclusions: Both maternal undernutrition and overnutrition of protein rich foods, junk foods, snack and energy foods and vegetable rich foods have shown a substantial varying effects on those infants with birthweights in the lower and upper birthweight quantiles.

Keywords: Cohort, Low birthweight, Food frequency questionnaire, Interaction effect, Ordinary regression, Quantile regression

\footnotetext{
* Correspondence: mitkua@ukzn.ac.za

${ }^{1}$ School of Mathematics, Statistics and Computer Science, College of

Agriculture Engineering and Science, University of KwaZulu-Natal, Durban,

South Africa

${ }^{4}$ Department of Statistics, Bahir Dar University, Bahir Dar, Ethiopia

Full list of author information is available at the end of the article
}

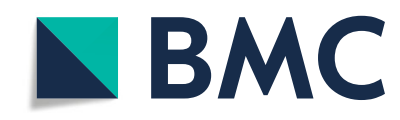

(C) The Author(s). 2020 Open Access This article is licensed under a Creative Commons Attribution 4.0 International License, which permits use, sharing, adaptation, distribution and reproduction in any medium or format, as long as you give appropriate credit to the original author(s) and the source, provide a link to the Creative Commons licence, and indicate if changes were made. The images or other third party material in this article are included in the article's Creative Commons licence, unless indicated otherwise in a credit line to the material. If material is not included in the article's Creative Commons licence and your intended use is not permitted by statutory regulation or exceeds the permitted use, you will need to obtain permission directly from the copyright holder. To view a copy of this licence, visit http://creativecommons.org/licenses/by/4.0/. The Creative Commons Public Domain Dedication waiver (http://creativecommons.org/publicdomain/zero/1.0/) applies to the data made available in this article, unless otherwise stated in a credit line to the data. 


\section{Background}

Adequate nutrition is vital during pregnancy, both for improved maternal and child health. Women are at risk of having an inadequate nutritional status during pregnancy due to the high nutritional demands during pregnancy. Inadequate maternal nutrition during pregnancy is related to adverse birth outcomes, poor infant survival, respiratory disease in early childhood and then, later in life, cardiovascular diseases and obesity [1-6]. For women living in developing countries, poor quality and quantity of food are major factors for the increased risk of malnutrition during pregnancy [7]. Birthweight has been related to both short and long-term health outcomes and thus, is commonly used as proxy, for studying infant development [8].

Dietary pattern analysis has become a useful tool in epidemiological studies that pursue to better represent a holistic account of the diet $[9,10]$ and explore the relationship between dietary exposures and health outcomes [11]. It allows the formulation of food-based dietary recommendations [12]. However, individual diets are usually composed of variety of different food items which contain a multitude of nutrients and phytochemicals that function both synergistically and interactively [9]. Dietary patterns characterized by high intakes of vegetables, fruit and dairy products were associated with higher birthweight. Dietary patterns related to low birthweight were often characterized by high loadings of processed and high-fat meat, fats and oils, and sugar rich products in high-income countries [13].

Previous studies showed nutritional status of mothers [14-16] and socio-demographic [16] factors had an association with birthweight. Both very high and very low birthweights are associated with detrimental outcomes. Therefore, modelling risk factors associated with solely lower or upper birthweights using techniques such as linear regression is not necessarily appropriate. Thus, the aim of this study is to assess the effect of maternal dietary pattern on the birthweight quintiles by adjusting the effect of socio-demographic factors.

Most of the statistical techniques used in previous studies for estimating the effect of continuous responses were either with conditional means [17] or through dichotomization, a common practice in epidemiological research. Despite the clinical usefulness contained in the dichotomized outcome, this practice of only considering two outcomes leads to a loss of power and information, due to the choice of the cut-off point of these dichotomous variable [18-20]. Using quantile regression instead of the common methods linear or logistic regression models led to new insights in the data sets [21-24]. In health sciences, quantile regression has become popular in relation to studies of body mass index [23-26]. Accordingly, we adopt quantile regression to model quantiles of birthweight on the nutritional status of mothers [14-16].

\section{Methods \\ Data}

The Mother and Child in the Environment (MACE) birth cohort study was conducted in Durban, South Africa. The study had enrolled a cohort of 996 pregnant women at three hospitals in the south (Wentworth Hospital, Prince Mshiyeni Hospital and King Edward VIII Hospital) and at three hospitals in the north (Addington and Mahathma Gandhi, and King George V Hospitals) from March 2013 up to May 2017. The field workers determined if the pregnant women met the inclusion criteria and all pregnant women that did, were invited and recruited into the study. The inclusion criteria were gestational age less than 20 weeks, resident for the full duration of the pregnancy in the geographical area within which the clinic and monitoring station was located, and for the follow-up period of 5-6years in the cohort. Women with multiple pregnancies as well as 309 miscarriages, loss to follow up and termination of pregnancy were excluded. This study is a retrospective analysis on the remainder 687 enrolled subjects who were followed up during their pregnancy, through to labour and delivery.

Socio-demographic information was taken from enrolment dataset which is conducted with face-to-face interviews by trained enumerators. The enrolment questionnaire also consists variables about antenatal history, place of birth and residential history. For the identification of maternal dietary patterns, a food frequency questionnaire (FFQ), which listed 75 items was administered in the third trimester of their pregnancy. The questionnaire collected information on the 75 food items common to maternal dietary situations during pregnancy. The FFQ specifically designed to reflect South African food consumption habits assessed the use of foods or food groups and the consumption frequency (number of times per day, week or month) as common serving sizes. The selected frequency category for each food item in the FFQ was standardized to times per day. The detailed content of the FFQ and data processing have been described elsewhere [15] and validated [27, 28]. Data was captured at the time of interview using a mobile telephone system, automatically uploading data onto the study database using wireless technology. In South Africa, iron and foliate supplements are standard and all mothers have got these supplements.

To reduce the 75 dietary food items from the FFQ into a set of manageable latent characteristics, with minimal loss of information, exploratory factor analysis of promax orthogonal rotation was performed. The absolute magnitude of the rotated factor loadings greater than 0.30 was used as a threshold value for a variable to belong to a latent group. A scree plot, along with the percentage of variance explained by each factor, resulted 
Table 1 Factor loadings of different food items in the eight latent dietary factors identified using factor analysis with Promax rotation

\begin{tabular}{|c|c|c|c|}
\hline Dietary patterns & Food items & Factor loadings coefficient* & Cumulative variance explained (\%) \\
\hline \multirow[t]{23}{*}{ "Snack and energy foods" } & Energy bars & 0.87486 & $46.41 \%$ \\
\hline & Energy drinks & 0.85251 & \\
\hline & Ice cream & 0.76687 & \\
\hline & Chocolate & 0.74735 & \\
\hline & Drinking yoghurt & 0.70387 & \\
\hline & Milk drinks & 0.70378 & \\
\hline & Milkshake & 0.66289 & \\
\hline & Fruit salad & 0.63208 & \\
\hline & Cheese sauce & 0.62704 & \\
\hline & Cheese & 0.56129 & \\
\hline & Chicken with skin & 0.47309 & \\
\hline & Chips & 0.46882 & \\
\hline & Cold meat & 0.46529 & \\
\hline & Red meat & 0.43206 & \\
\hline & Flame grilled fast food chicken & 0.42456 & \\
\hline & Hot dogs & 0.40035 & \\
\hline & Sausages & 0.39612 & \\
\hline & Fizzy soft drinks & 0.38538 & \\
\hline & Fruit juice & 0.35977 & \\
\hline & Hamburgers & 0.31074 & \\
\hline & Pizza & 0.30266 & \\
\hline & Rusks & 0.30247 & \\
\hline & Cooking oil & -0.33744 & \\
\hline \multirow[t]{20}{*}{ "Fast foods and spreads" } & Dripping & 0.76641 & $11.12 \%$ \\
\hline & Salad dressing low fat & 0.76498 & \\
\hline & Fat Holsum & 0.74403 & \\
\hline & Schnitzels & 0.70762 & \\
\hline & Skimmed & 0.6791 & \\
\hline & Chocolate spread & 0.60188 & \\
\hline & Bunny chow & 0.58556 & \\
\hline & Venison & 0.55576 & \\
\hline & Fizzy diet soft drinks & 0.51667 & \\
\hline & Fish steamed & 0.50548 & \\
\hline & Whole wheat & 0.49309 & \\
\hline & Dried fruit & 0.47822 & \\
\hline & Red meat fat removed & 0.47779 & \\
\hline & Cookies & 0.45296 & \\
\hline & Fried fast food chicken & 0.4281 & \\
\hline & Pasta & 0.42541 & \\
\hline & Organ meat & 0.40937 & \\
\hline & Nuts and peanuts & 0.36348 & \\
\hline & Pizza & 0.34863 & \\
\hline & Pies and sausage rolls & 0.34244 & \\
\hline
\end{tabular}


Table 1 Factor loadings of different food items in the eight latent dietary factors identified using factor analysis with Promax rotation (Continued)

\begin{tabular}{|c|c|c|c|}
\hline Dietary patterns & Food items & Factor loadings coefficient* & Cumulative variance explained (\%) \\
\hline & Vetkoek & 0.33541 & \\
\hline & Rusks & 0.32428 & \\
\hline & Hot dogs & 0.31508 & \\
\hline & Butter & 0.3194 & \\
\hline & Fizzy soft drinks & -0.31292 & \\
\hline \multirow[t]{15}{*}{ "Junk foods" } & Butter & 0.62300 & $10.45 \%$ \\
\hline & Sweets & 0.60625 & \\
\hline & Muffins & 0.59219 & \\
\hline & Chips & 0.56772 & \\
\hline & Mixed salad & 0.56106 & \\
\hline & Fruit juice & 0.5389 & \\
\hline & Fresh fruit & 0.53471 & \\
\hline & Fizzy soft drinks & 0.42281 & \\
\hline & Vetkoek & 0.39649 & \\
\hline & Coffee creamer & 0.38703 & \\
\hline & Cooking oil & 0.38482 & \\
\hline & Hamburgers & 0.36097 & \\
\hline & Cooked vegetables & 0.35781 & \\
\hline & Cereals Rice Crispies & 0.31854 & \\
\hline & Soft margarine & -0.77394 & \\
\hline \multirow[t]{9}{*}{ "Protein rich foods" } & Fried fish & 0.67237 & $6.35 \%$ \\
\hline & Fish tinned & 0.54825 & \\
\hline & Fried fish in fat & 0.52289 & \\
\hline & Eggs cooked or poached & 0.46767 & \\
\hline & White brown bread & 0.43925 & \\
\hline & Potato chips & 0.4079 & \\
\hline & Chicken with skin & 0.40252 & \\
\hline & Chicken without skin & -0.34525 & \\
\hline & Red meat fat removed & -0.40646 & \\
\hline \multirow[t]{9}{*}{ "Starch foods" } & Potato & 0.66418 & $4.56 \%$ \\
\hline & Breakfast cereals & 0.52251 & \\
\hline & Potato with fat & 0.47055 & \\
\hline & Legumes & 0.45527 & \\
\hline & Full cream & 0.40847 & \\
\hline & Cooked vegetables & 0.36178 & \\
\hline & Cheese sauce & 0.35377 & \\
\hline & Pasta & 0.32992 & \\
\hline & Jam & 0.32221 & \\
\hline \multirow[t]{3}{*}{ "Nuts and rice foods" } & Peanut butter & 0.55276 & $3.63 \%$ \\
\hline & Nuts and peanuts & 0.39124 & \\
\hline & Rice mealie rice & 0.34955 & \\
\hline \multirow[t]{2}{*}{ "Vegetable rich foods" } & Vegetables & 0.61485 & $3.13 \%$ \\
\hline & Organ meat & 0.40243 & \\
\hline
\end{tabular}


Table 1 Factor loadings of different food items in the eight latent dietary factors identified using factor analysis with Promax rotation (Continued)

\begin{tabular}{llll}
\hline Dietary patterns & Food items & Factor loadings coefficient* & Cumulative variance explained (\%) \\
\hline \multirow{3}{*}{ "Alcoholic drinks" } & Butter & -0.34338 & \\
& Shooters & 0.80795 & $2.67 \%$ \\
& Cocktails & 0.79207 & \\
\hline
\end{tabular}

*Factor loadings $\geq 3.0$ or $\leq-3.0$. Food groups are sorted by size of loading coefficients

eight latent dietary factors for further analyses. Collectively these factors explained $88.33 \%$ of the variability within the sample. The summary result with the factor loadings and naming of the latent factors is given in Table 1.

\section{Statistical analysis}

We explored the data on quantiles of birthweight and observed that extreme birthweight outcomes occur over several maternal strata; including marital status, educational level, employment status and annual income, as well as infant strata, specifically gender. The quantile regression model provides the effects of maternal diet across the distribution of birthweight taking into consideration outliers. In other words, the quantile e regression is particularly useful with data that are heterogeneous in that the tails and the central location of the conditional distributions vary differently with the covariates [22]. The effect of covariates on quantiles of the response distribution are pertinent. The covariates considered in this study were the eight latent dietary factors and sociodemographic factors. Quantile regression for a set of covariates, $\mathrm{X}$, on the $(\boldsymbol{\tau} \times \mathbf{1 0 0})^{\text {th }}$ quantiles of $\mathrm{y}$ is given by

$$
Q_{\tau}(y / X)=X^{t} \beta(\tau)+\varepsilon
$$

where $0<\tau<1$ and $\varepsilon=\left(\varepsilon_{1}, \ldots, \varepsilon_{n}\right)^{t}$ is a vector of independent errors. The parameter estimates, $\boldsymbol{\beta}(\boldsymbol{\tau})$ have the same interpretation as those of any other linear model, i.e. each $\beta_{j}(\tau)$ coefficient can be interpreted as the marginal change in the $(\boldsymbol{\tau} \times \mathbf{1 0 0})^{t h}$ quantile, due to the marginal change in corresponding $j^{\text {th }}$ covariate $[22,29,30]$. The quantile regression coefficients are computed by minimizing the asymmetric weighted sum of absolute errors through linear programing methods:

$$
\min _{\beta}\left[\sum_{i: \beta_{i} \geq x^{\prime} \beta} \tau\left|\boldsymbol{\beta}_{i}-x_{i}^{\prime} \beta^{\boldsymbol{\tau}}\right|+\sum_{i: \beta_{i} \leq x^{\prime} \beta}(1-\tau)\left|\boldsymbol{\beta}_{i}-\boldsymbol{x}_{i}^{\prime} \boldsymbol{\beta}^{\boldsymbol{\tau}}\right|\right]
$$

The model was built by fitting all the main effects followed by sequential assessment of whether any interaction terms need to be incorporated in to the model. Consequently, only two two-way interaction term of employment status with marital status and maternal education improved the main effect quantile regression model fit. Outliers can adversely influence the fit of the model thereby invalidating the appropriate statistical inferences [31]. However, quantile regression is fairly robust to outliers as their influence functions are bounded in the Yspace [22]. Existence of single case outlier diagnostic can be checked based on the standardized median absolute deviation of residuals [32]. The robust and multivariate location and scale diagnostics computed using the minimum covariance determinant (MCD) method were applied to expose all the single case high leverage points and outliers [33]. We used the standardized residuals and Quantile-Quantile plots for checking the goodness of fit of the model. All the statistical analyses were performed using SAS, version 9.4.

\section{Results}

The overall mean birthweight of the 687 children in the birth cohort was $3107.0 \mathrm{~g}$ (g) with a median of $3140.0 \mathrm{~g}$. The data included 357 male and 328 female infants, with $80.6 \%$ of mothers being single and $79.5 \%$ with high school education. Majority of the women in the cohort were unemployed (81.5\%), have no personal income $(47.9 \%)$ and $48.8 \%$ of them were nulliparous. The $95^{\text {th }}$ quantile of birthweight was higher in infants born to women who were married, primary or less education or were primaparous. Male offspring, older maternal age, lower education were observed to have lower birthweight at $5^{\text {th }}$ quantile. The quantiles of birthweight by socio-demographic characteristics are summarized in Table 2.

Table 3 shows the results from estimation of the final quantile regression model and ordinary least squares regression. Before we make any inference from the model results we examine its goodness of fit. All the goodness of fit assessment results in Fig. 1 showed that the final model fits the data adequately.

From Table 3, the confidence intervals of the ordinary regression and the quantile regression at the $50^{\text {th }}$ quantile have a considerable overlap. Otherwise quantile regression estimates confidence intervals lie outside the confidence intervals for the ordinary least squares regression, suggesting that the effects of these covariates may not be constant across the conditional distribution quantiles. And hence justifies the importance of quantile regression to have a better picture in the whole spectrum of the birthweight quantile. 
Table 2 Descriptive statistics and quantiles of birthweight by socio-demographic characteristics of women in MACE birth cohort

\begin{tabular}{|c|c|c|c|c|c|c|c|c|}
\hline Variable & $\mathrm{N}(\%)$ & $P_{5}$ & $P_{10}$ & $\mathrm{P}_{25}\left(\mathrm{Q}_{1}\right)$ & Median & $\mathrm{P}_{75}\left(\mathrm{Q}_{3}\right)$ & $P_{90}$ & $P_{95}$ \\
\hline \multicolumn{9}{|l|}{ Marital status } \\
\hline Married & $93(13.6)$ & 2084 & 2400 & 2900 & 3300 & 3560 & 3990 & 4031 \\
\hline Living together & $39(5.7)$ & 2080 & 2400 & 2800 & 3112 & 3430 & 3800 & 3970 \\
\hline Single & $554(80.8)$ & 2090 & 2400 & 2840 & 3115 & 3400 & 3720 & 3980 \\
\hline \multicolumn{9}{|l|}{ Maternal age } \\
\hline Teenage (less than $25 \mathrm{yrs}$ ) & $116(16.9)$ & 2070 & 2331 & 2740 & 3060 & 3300 & 3560 & 3640 \\
\hline Prime of fertility (25-29yrs) & $416(60.6)$ & 2100 & 2440 & 2876 & 3160 & 3430 & 3800 & 4000 \\
\hline Adult age ( 30 years and above) & $155(22.6)$ & 2031 & 2340 & 2800 & 3170 & 3400 & 3800 & 4000 \\
\hline \multicolumn{9}{|l|}{ Maternal education } \\
\hline Primary or less & $16(2.3)$ & 1570 & 1800 & 2775 & 3210 & 3495 & 3870 & 4260 \\
\hline Secondary school & $546(79.5)$ & 2083 & 2400 & 2815 & 3105 & 3400 & 3710 & 3920 \\
\hline College or university & $125(18.2)$ & 2096 & 2410 & 2960 & 3210 & 3480 & 3970 & 4120 \\
\hline \multicolumn{9}{|l|}{ Employment } \\
\hline Employed & $127(18.5)$ & 2080 & 2360 & 2820 & 3100 & 3480 & 3850 & 4010 \\
\hline Unemployed & $560(81.5)$ & 2090 & 2400 & 2860 & 3140 & 3400 & 3730 & 4000 \\
\hline \multicolumn{9}{|l|}{ Maternal annual income } \\
\hline No personal income & $329(47.9)$ & 2090 & 2400 & 2885 & 3160 & 3400 & 3800 & 4000 \\
\hline Less than R30000 & $276(40.2)$ & 2090 & 2400 & 2800 & 3100 & 3400 & 3700 & 3980 \\
\hline R30000 and above & $82(11.9)$ & 2083 & 2530 & 2840 & 3150 & 3480 & 3800 & 3970 \\
\hline \multicolumn{9}{|l|}{ Parity } \\
\hline Nulliparous & $334(48.8)$ & 2080 & 2360 & 2790 & 3100 & 3340 & 3630 & 3850 \\
\hline Primaparous & $220(32.1)$ & 2079 & 2060 & 2870 & 3230 & 3500 & 3895 & 4045.5 \\
\hline Multiparous & $131(19.1)$ & 2280 & 2500 & 2900 & 3150 & 3410 & 3800 & 3990 \\
\hline \multicolumn{9}{|l|}{ Infant Gender } \\
\hline Male & $359(52.3)$ & 2084 & 2370 & 2860 & 3170 & 3450 & 3900 & 4060 \\
\hline Female & $328(47.7)$ & 2090 & 2410 & 2830 & 3125 & 3370 & 3600 & 3810 \\
\hline
\end{tabular}

In order to avoid redundancy in the interpretation of the results in Table 3 and Fig. 2, we interpret few. Vegetable rich foods consumption during pregnancy increased birthweight at lower quantiles. This increase was significant at the $5^{\text {th }}$ quantile $(p=0.001)$. However, in the $95^{\text {th }}$ quantile, increase in consumption of vegetable rich foods had resulted in birthweight reduction. An increased frequency of junk foods intake by mothers was also associated with a slight increase in birthweight at the lower quantiles and significantly higher increase at the $95^{\text {th }}$ quantile $(p<0.001)$. The results also indicated that consumption of snack and energy foods $(p=0.001)$, nuts and rice foods $(p<0.001)$ and junk foods $(\mathrm{p}<0.001)$ during pregnancy increased the infant birthweight at the $95^{\text {th }}$ quantiles of birthweight. Similarly, higher frequency of consuming nuts and rice foods by mothers is associated with increased birthweight in the $50^{\text {th }}$ quantile $(p=0.021)$.

Mothers who consume protein rich foods with a higher frequency, tend to give birth to infants with significantly lower birthweight, as evidenced in the $5^{\text {th }}$ and $95^{\text {th }}$ quantile $(p<0.001)$. However, an increased frequency of protein rich foods intake increased birthweight of an infant at the $75^{\text {th }}$ and $90^{\text {th }}$ quantiles. Female infants had a lower birthweight at the upper quantiles $(p<0.001)$ than males.

The two-way significant interactions were maternal employment status with marital status and maternal employment status with maternal education (Fig. 3). Infants born to employed women with marital status of living together weighed less than infants born to married mothers in the lower tail of the birthweight distribution but are more likely to have high birthweight at the upper tail quantiles. The interaction between maternal employment and education had a large positive effect on birth weight, especially in the lower tail; this difference is smaller in the upper quantiles of the distribution. For instance, at the $5^{\text {th }}$ and $10^{\text {th }}$ quantiles, infants from employed mothers with some primary school or less education, had $1670 \mathrm{~g}(p<0.001)$ and $1824 \mathrm{~g}(\mathrm{p}<0.001)$ 


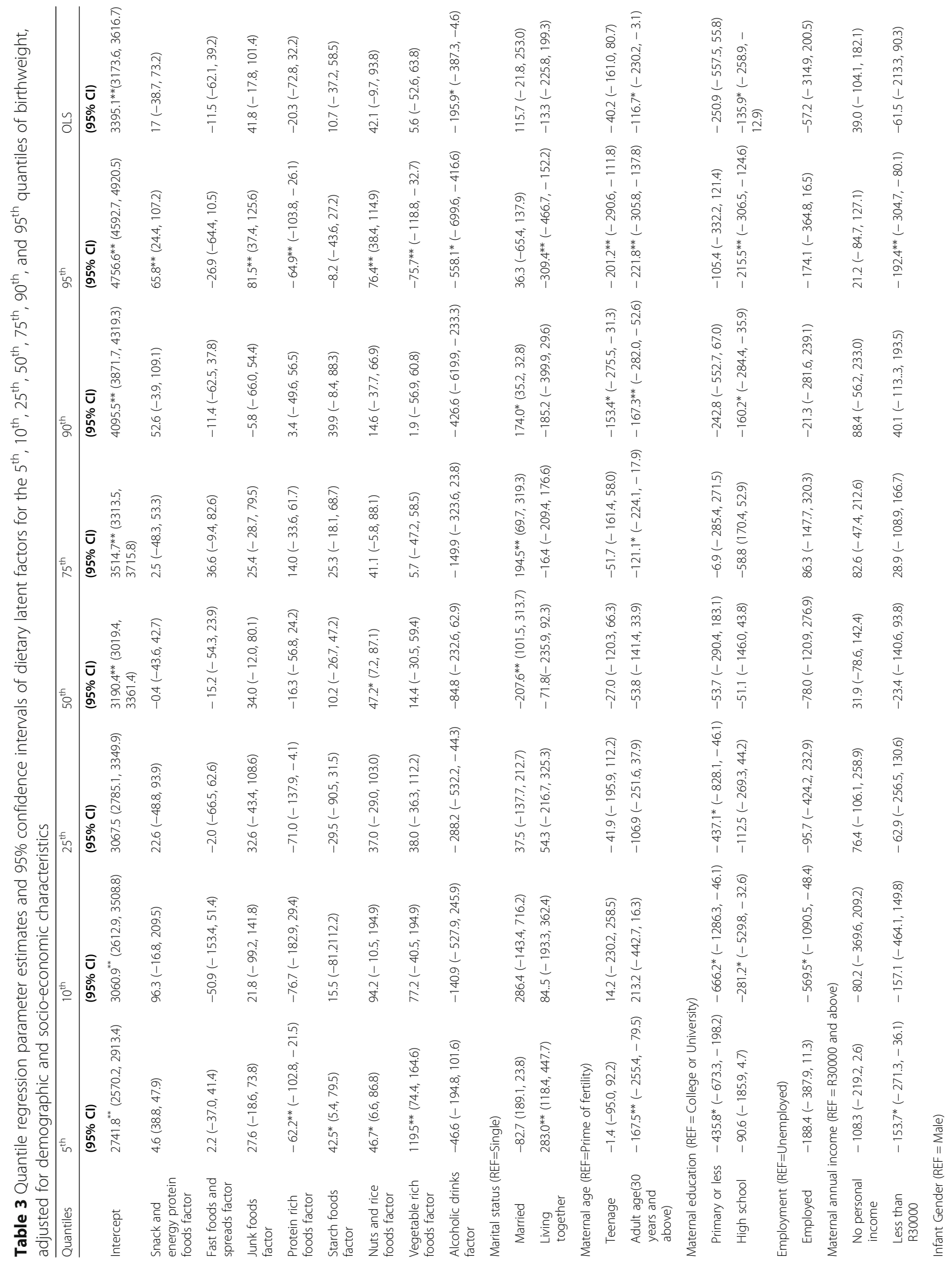




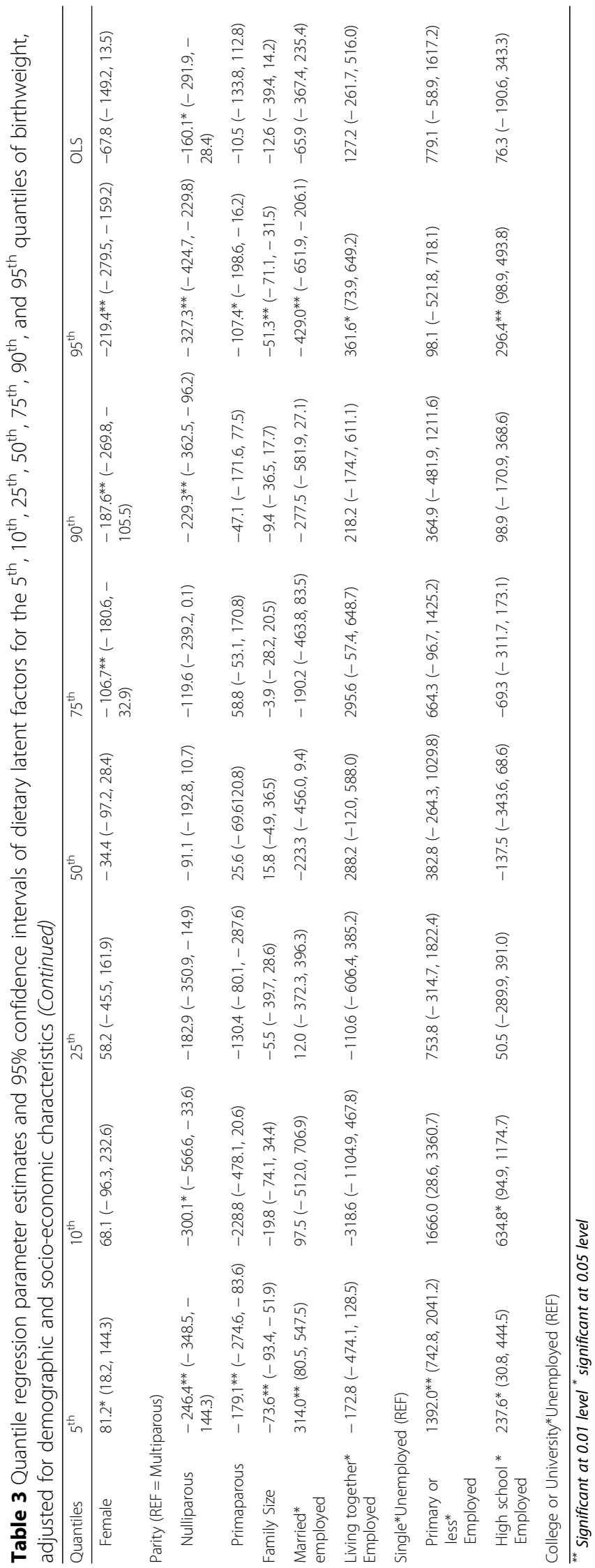



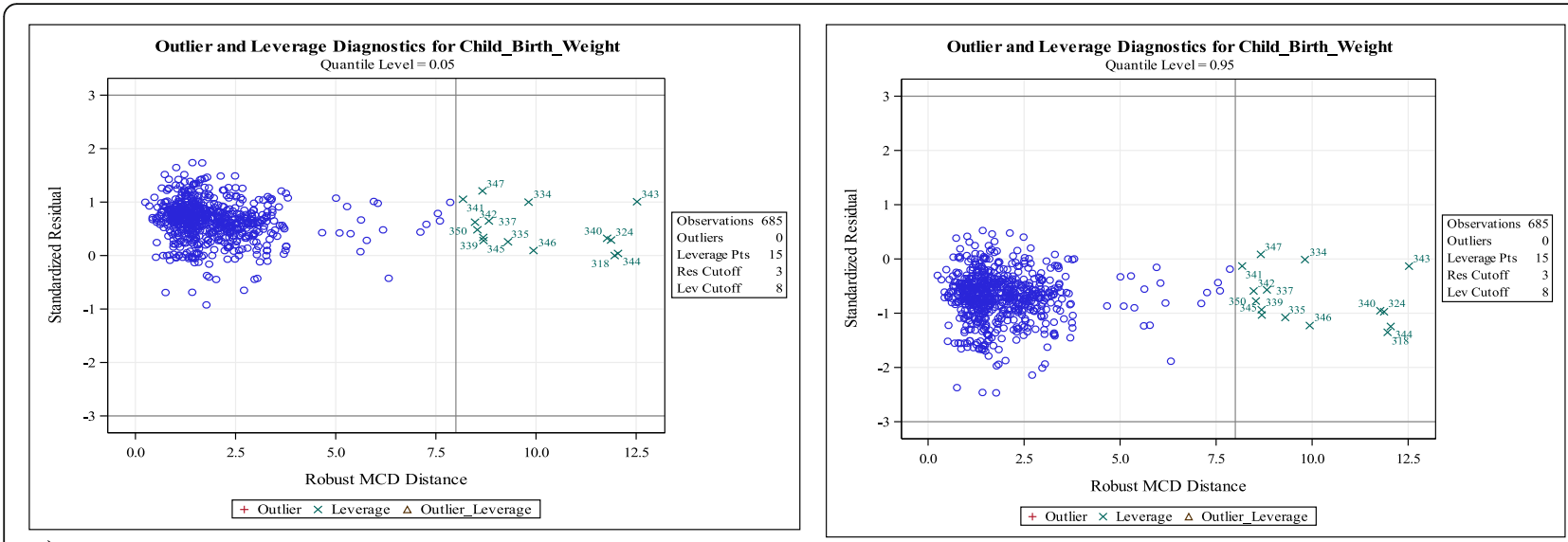

a)
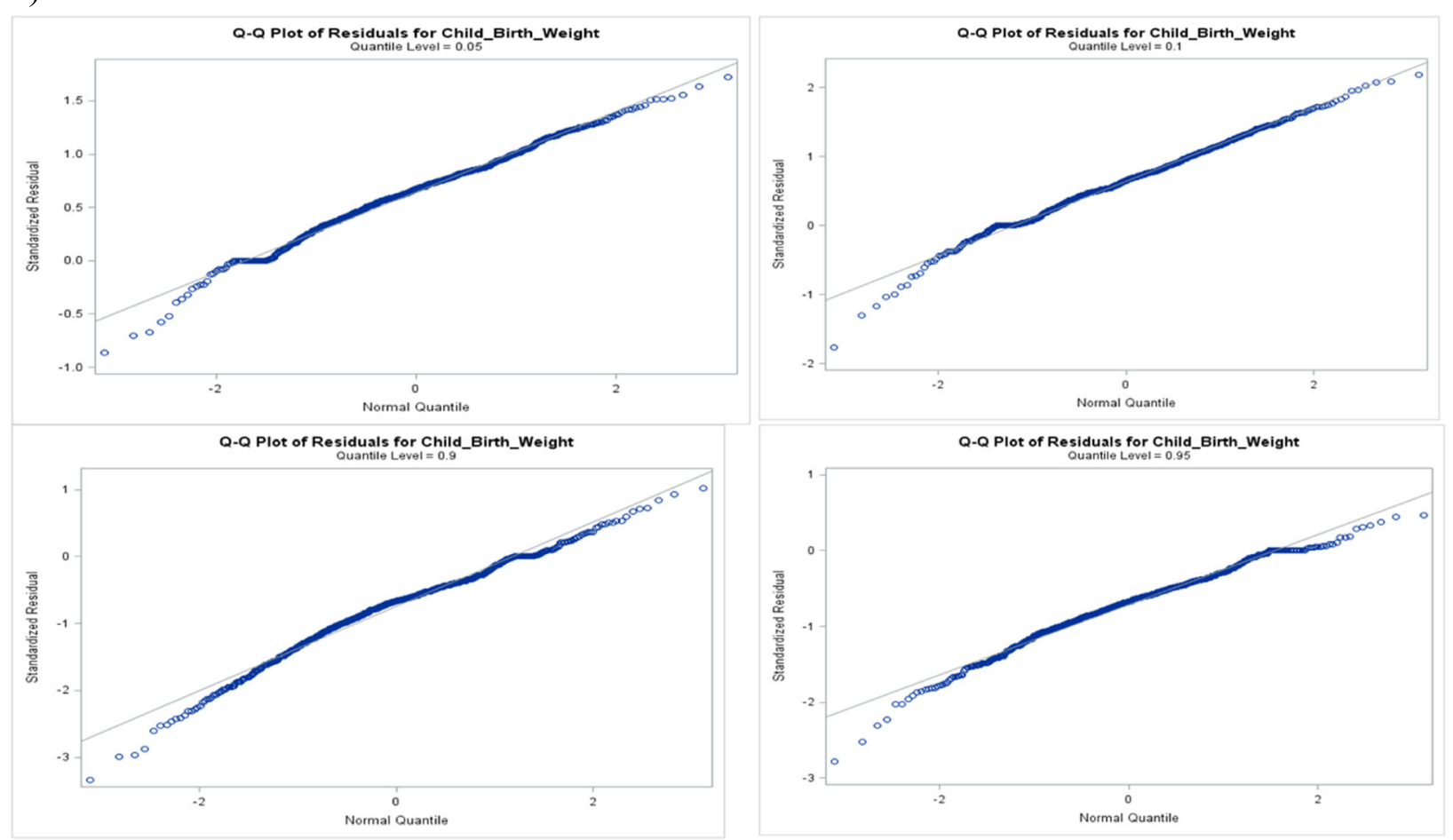

b)

Fig. 1 Diagnostic plots for the final quantile regression model

higher birthweights respectively than those from unemployed mothers with college or university education.

\section{Discussion}

This study showed, through the use of novel statistical approach, that protein rich foods dietary pattern had significant differential effects in the lower and upper quantiles of birthweight in Durban, South Africa. Our findings further suggest that vegetable rich foods and starch foods dietary patterns showed a protective effect at the $5^{\text {th }}$ quantile of birthweight. Quantile regression models allowed for exploration of differential effects of dietary patterns across quantiles of birthweight adjusting for important demographic and socio-economic factors in MACE birth cohort. The differential effect of dietary patterns on quantiles of birthweight has not been previously described.

Previous studies that examined the association between maternal dietary patterns during pregnancy and birth outcomes, particularly in the presence of a high burden of low birthweights in the data set, used ordinary least square and logistic regression [11, 15, 17, 34]. The quantile regression insight on differential effect of maternal dietary on the different quantiles of birthweight.

Consumption of a traditional dietary pattern (potatoes, meat, vegetables) in early pregnancy, has been found in 

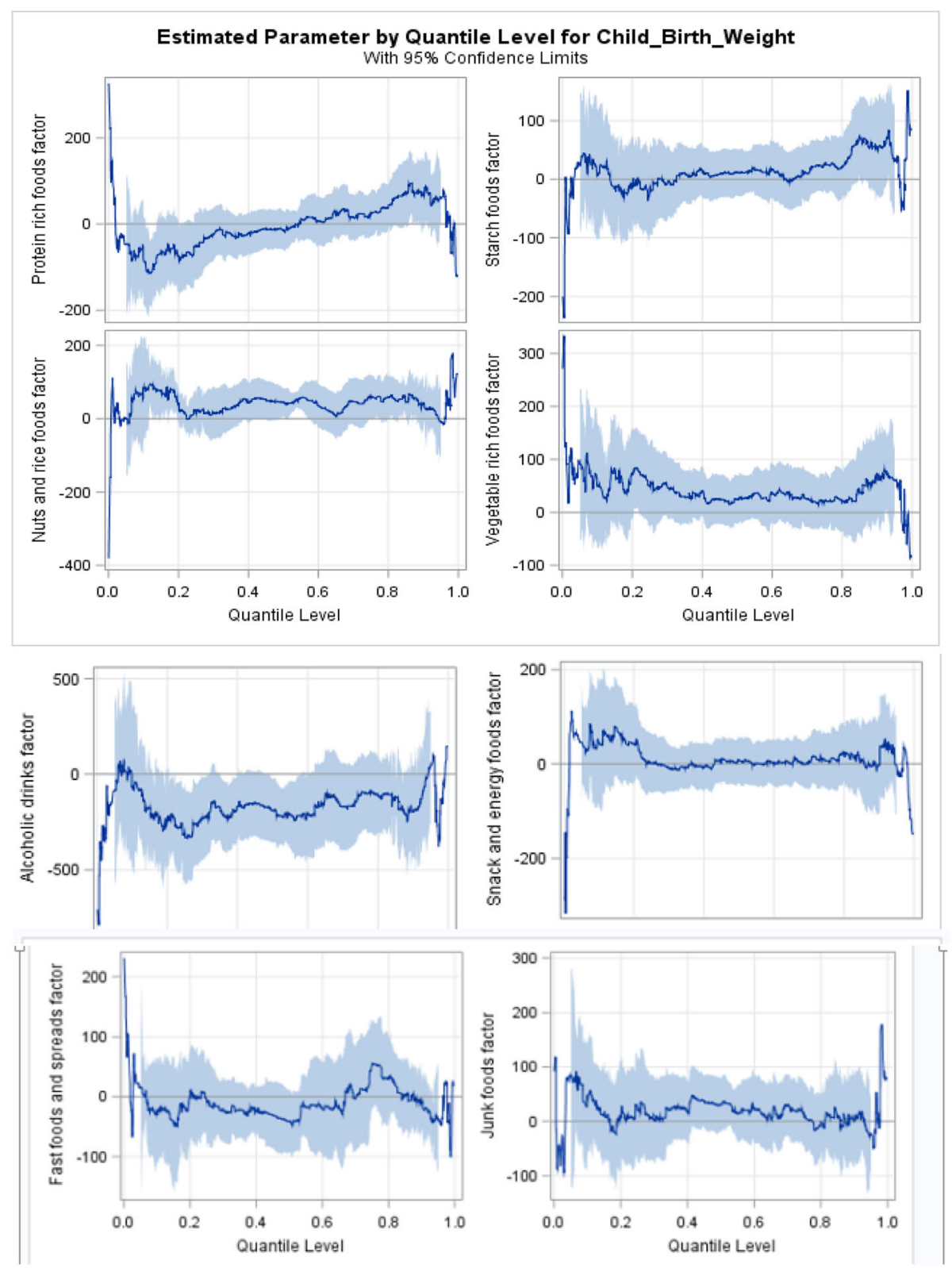

Fig. 2 Differential effect of dietary patterns across quantiles of birthweight in the cohort of pregnant women

other studies to reduce the risk of having a low birthweight infant $[11,17]$. Our study found further evidence in support of these studies, with consumption of vegetable rich foods and starch foods having a protective effect at the $5^{\text {th }}$ quantile of birthweight. Unlike to these studies, our findings found that consumption of vegetable rich foods had associated with birthweight reduction at the $95^{\text {th }}$ quantile. However, this is consistent with a study among British women that found processed and vegetarian diets were associated with the lowest birthweight [35]. A study in Brazil demonstrated that snack dietary patterns of mothers was associated with increase in birthweight [34]. In line with this, our findings showed increased intake of snack and energy foods by mothers during their pregnancy was associated with increased birthweight at lower and upper tail of birthweight. A review on studies from high-income countries found junk foods dietary pattern is related to low birthweight [13]. On the contrary, the findings of our study indicated that maternal consumption of junk foods during pregnancy was associated with increased offspring birthweight at the $95^{\text {th }}$ quantile. In line with our study, junk food diet characterized by high consumption of fast foods, soft drink, processed meat, or chips frequently 


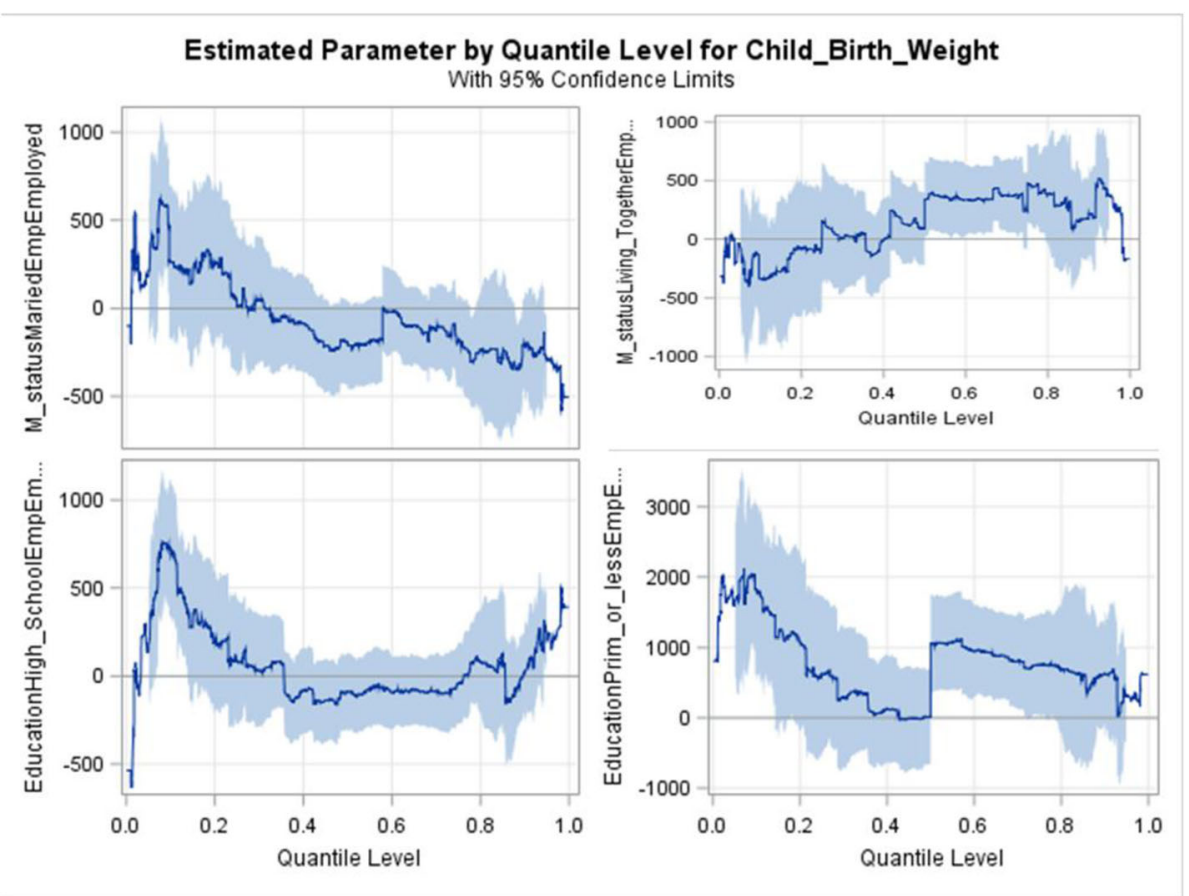

Fig. 3 Association between interaction estimates of employment status with marital status and education of pregnant women across different quantiles of birthweight

during pregnancy was associated increased risk of having a baby with a high birthweight in Australia [36].

In the $5^{\text {th }}$ quantile, our study revealed that consumption of protein rich foods by mothers is associated with decreased birthweight. This is similar to what was found in studies in Ghana and Denmark, which indicated that red and processed meat diets during pregnancy, was associated with an increased risk of infants with lower birthweights $[15,37]$. It is also noted that in a lowincome cohort of US women, high protein intake was associated with reduced birth weight [38]. Moreover, the quantile regression modeling in our study showed evidence of a varied effect of protein rich foods consumed by mothers, throughout the conditional distribution of birthweight. For instance, women with more frequent consumption of protein rich foods, were associated with giving birth to infants with increased birthweight at the $75^{\text {th }}$ and $90^{\text {th }}$ quantile and these association was with a reduced birthweight at the $95^{\text {th }}$ quantile.

Completing at least upper secondary education was found protective against low birthweight infants [39, 40]. Adverse socio-economic conditions such as maternal unemployment [40] and education level [41] have been linked to low birthweight in other studies. Unlike these studies, our study found an interaction effect of maternal employment with education and marital status. i.e. unemployed women with college or university education were more likely to have a low birthweight infant. The findings of the present study indicated that infants from employed and unmarried women, tend to have lower birthweight in the bottom lower $\left(5^{\text {th }}\right)$ quantile, but more likely to be macrosomia in the top upper tail $\left(95^{\text {th }}\right)$ quantile. This may be attributed to the job loadings on women during pregnancy. The quantile regression in this study showed that employment and family size had a differential effect across the different quantiles of birthweight. In higher quantiles of birthweight, female infants had consistently lower birthweight. This results corroborate what other authors who used linear regression [42] and logistic regression [43] found, i.e. male infants were more likely to be heavier at birth, compared with female infants.

An important strength of our study is that we were able to obtain detailed dietary data from an ongoing birth cohort, and using this rich dataset, we were able to describe, through factor analysis, a typical dietary pattern in a developing country, low socio-economic community utilizing both traditional and "western" dietary patterns. The additional strength of this study is that use of novel statistical approach, quantile regression, which is a very useful tool for data that are heterogeneous, in the sense that the tails and the central location of the conditional distributions vary differently with the levels of covariates and it is also robust, as it makes no distributional assumption about the error term in the model. A limitation of the study was the varying description of similar 
food types among participants (eg. the frequent use of trade names or local terms in describing intake), which may have resulted in high loading at different factors.

\section{Conclusions}

Food frequency questionnaires (FFQ) have been used in the study of dietary patterns among pregnant females. The advantage of this approach is that it identifies local dietary intake. In order to minimize the recall bias, the dietary data was collected in the third trimester of pregnancy, not at neonatal. Exploratory factor analysis data reduction was employed to transform the large set of correlated variables into smaller sets of non-correlated variables, known as factors, allowing a better understanding of the dimensions underlying the initial variables. Quantile regression allowed modeling the differential effect of maternal dietary patterns adjusting for socio-demographics on the entire quantile of birthweight spectrum. This would have been missed if traditional regression methods had been employed as it models at the average birthweight. The quantile regression model identified substantially differential effects of protein rich foods, parity and infant gender in the lower and upper distribution of birthweight. Moreover, vegetable rich foods and starch foods dietary patterns showed a protective effect at the $5^{\text {th }}$ quantile of birthweight. Future studies need to consider other indicators such as gestational age, birth length and head circumference as measures of birth outcomes to better explore the effects of maternal dietary patterns.

\section{Abbreviations}

FFQ: Food Frequency Questionnaires; MACE: Mother and Child in the Environment; MCD: Minimum Covariance Determinant

\section{Acknowledgements}

We wish to acknowledge the Mother and Child in the Environment cohort study participants, all study fieldworkers and nursing staff at the participating clinics and hospitals. We also sincerely thank all the international collaborators (Utrecht, Michigan) and local collaborators of the MACE Study.

\section{Authors' contributions}

AAM, TZ and RNN conceptualized the research problem. AAM, TZ, DN and RNN developed the study design. AAM organized the data, conducted the statistical analysis and drafted the manuscript. PJ and RNN were responsible for the child outcomes data. All authors critically reviewed and made substantial contributions to the manuscript. All authors read, commented and approved the final manuscript.

\section{Funding}

The Mother and Child in the Environment Cohort study is funded by the National Research Foundation (grant number: 90550), Medical Research Council, South Africa, AstraZeneca, South Africa and the College of Health Sciences. The funders played no role in the design and conduct of the study, or the data analysis and drafting of the manuscript.

\section{Availability of data and materials}

The data that support the findings of this study are available from MACE study but restrictions apply to the availability of these data, which were used under license for the current study, and so are not publicly available. Data are however available from the authors upon reasonable request and with permission from MACE study.

\section{Ethics approval and consent to participate}

Written, informed consent was obtained from the mother for the children and provided their own consent. Follow-ups of the study were approved by the respective ethics committees at the University of KwaZulu-Natal Medical School.

\section{Consent for publication}

Not applicable.

\section{Competing interests}

All authors declare that they have no any competing interests.

\section{Author details}

${ }^{1}$ School of Mathematics, Statistics and Computer Science, College of Agriculture Engineering and Science, University of KwaZulu-Natal, Durban, South Africa. ${ }^{2}$ Discipline of Paediatric and Child Health, School of clinical Medicine, College of Health Sciences, University of KwaZulu-Natal, Durban, South Africa. ${ }^{3}$ Discipline of Occupational and Environmental Health, School of Nursing and Public Health, College of Health Sciences, University of KwaZulu-Natal, Durban, South Africa. ${ }^{4}$ Department of Statistics, Bahir Dar University, Bahir Dar, Ethiopia.

Received: 2 October 2019 Accepted: 5 June 2020

Published online: 22 June 2020

\section{References}

1. Abu-Saad K, Fraser D. Maternal nutrition and birth outcomes. Epidemiol Rev. 2010:32(1):5-25.

2. Black RE, Allen LH, Bhutta ZA, Caulfield LE, De Onis M, Ezzati M, Mathers C, Rivera J. Maternal, group CUS: maternal and child undernutrition: global and regional exposures and health consequences. Lancet. 2008;371(9608):24360.

3. Pauwels S, Doperé I, Huybrechts I, Godderis L, Koppen G, Vansant G. Reproducibility and validity of an FFQ to assess usual intake of methylgroup donors. Public Health Nutr. 2015;18(14):2530-9.

4. Pike K, Rose-Zerilli M, Osvald EC, Inskip H, Godfrey KM, Crozier S, Roberts G, Clough J, Holloway JW, Lucas J. The relationship between infant lung function and the risk of wheeze in the preschool years. Pediatr Pulmonol. 2011;46(1):75-82.

5. Gluckman PD, Hanson MA, Cooper C. In utero and early-life conditions and adult health and disease. N Engl J Med. 2008;359(14):1524.

6. Inskip HM, Crozier SR, Godfrey KM, Borland SE, Cooper C, Robinson SM. Women's compliance with nutrition and lifestyle recommendations before pregnancy: general population cohort study. Bmj. 2009;338:b481.

7. Lee SE, Talegawkar SA, Merialdi M, Caulfield LE. Dietary intakes of women during pregnancy in low-and middle-income countries. Public Health Nutr. 2013;16(8):1340-53.

8. Gortmaker SL, Peterson K, Wiecha J, Sobol AM, Dixit S, Fox MK, Laird N. Reducing obesity via a school-based interdisciplinary intervention among youth: planet health. Archives of pediatrics \& adolescent medicine. 1999; 153(4):409-18.

9. Moeller SM, Reedy J, Millen AE, Dixon LB, Newby P, Tucker KL, Krebs-Smith SM, Guenther PM. Dietary patterns: challenges and opportunities in dietary patterns research: an experimental biology workshop, April 1, 2006. J Acad Nutr Diet. 2007;107(7):1233-9.

10. Jacques PF, Tucker KL. Are dietary patterns useful for understanding the role of diet in chronic disease? In: Oxford University Press. 2001.

11. Thompson JM, Wall C, Becroft DM, Robinson E, Wild CJ, Mitchell EA. Maternal dietary patterns in pregnancy and the association with small-forgestational-age infants. Br J Nutr. 2010;103(11):1665-73.

12. Timmermans $S$, Steegers-Theunissen RP, Vujkovic $M$, den Breeijen $H$, Russcher H, Lindemans J, Mackenbach J, Hofman A, Lesaffre EE, Jaddoe W. The Mediterranean diet and fetal size parameters: the generation $\mathrm{R}$ study. $\mathrm{Br}$ J Nutr. 2012;108(8):1399-409.

13. Kjøllesdal MK, Holmboe-Ottesen G. Dietary patterns and birth weight-a review. AIMS public health. 2014;1(4):211.

14. Ali F, Thaver I, Khan SA. Assessment of dietary diversity and nutritional status of pregnant women in Islamabad, Pakistan. Journal of Ayub Medical College Abbottabad. 2014;26(4):506-9.

15. Abubakari A, Jahn A. Maternal dietary patterns and practices and birth weight in northern Ghana. PLoS One. 2016;11(9):e0162285. 
16. Kader M, Perera NKP. Socio-economic and nutritional determinants of low birth weight in India. N Am J Med Sci. 2014;6(7):302.

17. Bouwland-Both M, Steegers-Theunissen R, Vujkovic M, Lesaffre E, MookKanamori D, Hofman A, Lindemans J, Russcher H, Jaddoe V, Steegers E. A periconceptional energy-rich dietary pattern is associated with early fetal growth: the generation R study. BJOG Int J Obstet Gynaecol. 2013;120(4): 435-45.

18. Ragland DR. Dichotomizing continuous outcome variables: dependence of the magnitude of association and statistical power on the cutpoint. Epidemiology. 1992:434-40.

19. Altman DG, Royston P. The cost of dichotomising continuous variables. Bmj. 2006;332(7549):1080

20. Peacock J, Sauzet O, Ewings S, Kerry S. Dichotomising continuous data while retaining statistical power using a distributional approach. Stat Med. 2012;31(26):3089-103.

21. Dahly DL, Li X, Smith HA, Khashan AS, Murray DM, Kiely ME, O'B Hourihane J, McCarthy FP, Kenny LC, Kearney PM. Associations between maternal lifestyle factors and neonatal body composition in the screening for pregnancy endpoints (Cork) cohort study. Int J Epidemiol. 2017;47(1):131-45.

22. Koenker R, Bassett G: Regression quantiles. Econometrica 46 33-50. Mathematical Reviews (MathSciNet): MR474644 Digital Object Identifier: doi 1978, 10:1913643.

23. Chae S-M, Kim MJ, Park CG, Yeo J-Y, Hwang J-H, Kwon I, Han S-Y. Association of Weight Control Behaviors with body mass index in Korean adolescents: a Quantile regression approach. J Pediatr Nurs. 2018;40:e18-25.

24. Gebremariam MK, Arah OA, Lien N, Naess O, Ariansen I, Kjollesdal MK. Change in BMI distribution over a 24-year period and associated socioeconomic gradients: a Quantile regression analysis. Obesity. 2018;26(4): 769-75.

25. Terry MB, Wei Y, Esserman D. Maternal, birth, and early-life influences on adult body size in women. Am J Epidemiol. 2007;166(1):5-13.

26. Sturm R, Datar A. Body mass index in elementary school children, metropolitan area food prices and food outlet density. Public Health. 2005; 119(12):1059-68.

27. Sheehy T, Kolahdooz F, Mtshali T, Khamis T, Sharma S. Development of a quantitative food frequency questionnaire for use among rural $S$ outh a fricans in K Wa Z ulu-N atal. J Hum Nutr Diet. 2014;27(5):443-9.

28. Zingoni C, Norris SA, Griffiths PL, Cameron N. Studying a population undergoing nutrition transition: a practical case study of dietary assessment in urban south African adolescents. Ecology of food and nutrition. 2009; 48(3):178-98.

29. Koenker R: Quantile regression. In.: Cambridge University Press, New York; 2005.

30. Koenker R, Hallock KF. Quantile regression. J Econ Perspect. 2001;15(4): 143-56.

31. Rousseeuw PJ, Leroy AM: Robust regression and outlier detection, vol. 589: John wiley \& sons; 2005.

32. Huber PJ, Ronchetti EM: Robust statistics. hoboken. NJ: Wiley doi 2009, 10(1002):9780470434697.

33. Rousseeuw PJ, Driessen KV. A fast algorithm for the minimum covariance determinant estimator. Technometrics. 1999;41(3):212-23.

34. Coelho NdLP, Cunha DB, Esteves APP, Lacerda EMdA, Theme Filha MM: Dietary patterns in pregnancy and birth weight. Revista de saude publica 2015, 49:62.

35. Northstone K, Ness A, Emmett P, Rogers I. Adjusting for energy intake in dietary pattern investigations using principal components analysis. Eur J Clin Nutr. 2008;62(7):931.

36. Wen LM, Simpson JM, Rissel C, Baur LA. Maternal "junk food" diet during pregnancy as a predictor of high birthweight: findings from the healthy beginnings trial. Birth. 2013;40(1):46-51.

37. Knudsen V, Orozova-Bekkevold I, Mikkelsen TB, Wolff S, Olsen S. Major dietary patterns in pregnancy and fetal growth. Eur J Clin Nutr. 2008;62(4): 463.

38. Sloan NL, Lederman SA, Leighton J, Himes JH, Rush D. The effect of prenatal dietary protein intake on birth weight. Nutr Res. 2001;21(1-2): 129-39.

39. Tsimbos C, Verropoulou G. Demographic and socioeconomic determinants of low birth weight and preterm births among natives and immigrants in Greece: an analysis using nationwide vital registration micro-data. J Biosoc Sci. 2011;43(3):271-83.
40. Meggiolaro S. Low birth weight and parental resources in Italy. Genus. 2009; 65(2):103-21.

41. Fallah R, Kazemnejad A, Zayeri F, Shoghli A. Birthweight related factors in northwestern Iran: using Quantile regression method. Global J Health Sci. 2016;8(7):116.

42. Takimoto H, Yokoyama T, Yoshiike N, Fukuoka H. Increase in low-birthweight infants in Japan and associated risk factors, 1980-2000. J Obstet Gynaecol Res. 2005;31(4):314-22.

43. Ipadeola OB, Adebayo SB, Anyanti J, Jolayemi ET. Poverty levels and maternal nutritional status as determinants of weight at birth: an ordinal logistic regression approach. International Journal of Statistics and Applications. 2013;3(3):50-8.

\section{Publisher's Note}

Springer Nature remains neutral with regard to jurisdictional claims in published maps and institutional affiliations.
Ready to submit your research? Choose BMC and benefit from:

- fast, convenient online submission

- thorough peer review by experienced researchers in your field

- rapid publication on acceptance

- support for research data, including large and complex data types

- gold Open Access which fosters wider collaboration and increased citations

- maximum visibility for your research: over $100 \mathrm{M}$ website views per year

At BMC, research is always in progress.

Learn more biomedcentral.com/submissions 